\title{
A HISTÓRIA LOCAL E O SEU LUGAR NA PESQUISA EM HISTÓRIA DA EDUCAÇÃO
}

\author{
LA HISTORIA LOCAL Y SU LUGAR EN LA PESQUISA EN HISTORIA DE \\ LA EDUCACIÓN
}

\author{
Elenice Silva Ferreira \\ Professora Assistente da \\ Universidade Estadual do Sudoeste da Bahia - UESB \\ elenicesf@hotmail.com
}

\begin{abstract}
Resumo
O presente texto discorre acerca do debate teóricometodológico na questão da produção historiográfica em nível local/regional sem perder de vista a sua relação com o global, já que há muito a historiografia vem considerando que as realidades criadas pela ação do homem, sobre o espaço e no tempo, não podem ser analisadas apenas a partir de seus aspectos globalizantes, mas, também, a partir de suas particularidades e singularidades manifestadas, principalmente, em seu micro-espaço. Trata-se de uma postura teóricametodológica que se generalizou por meio da chamada Escola dos Annales, sobretudo em sua terceira geração, possibilitando a abertura de novas fronteiras interpretativas, ressignificando o conceito de fonte documental, de modo a promover outras vias para as pesquisas no campo da História, em especial, da História da Educação. Nessa perspectiva, a escrita da história da educação na dimensão local não deixa de reconhecer o município como instituição com vida própria, entretanto articulado com as ações políticas e educacionais em nível nacional/global, rompendo com a dicotomia entre o centro e a periferia, o local e o global, posto que um está contido no outro.
\end{abstract}

Palavras-chave: História Local. História da Educação. Annales. Pesquisa. 


\section{Resumen}

Este documento se centra en el debate teórico-metodológico de la historiografía en el nivel local/regional, sin perder de vista su relación con la historiografía mundial, considerando siempre las realidades creadas por el hombre, en el espacio y el tiempo, no pueden analizarse sólo desde sus aspectos de globalización, sino también desde sus peculiaridades y singularidades manifiestadas sobre todo en su micro-espacio. Este es un enfoque teórico y metodológico que se generalizo desde la Escuela de los Annales, especialmente en su tercera generación, posibilitando la apertura de nuevos límites interpretativos, dando un nuevo significado al concepto de fuente documental, con el fin de promover otras vías para la investigación en el campo de la Historia, especialmente en la Historia de la Educación. En esta perspectiva, la escritura de la Historia de la Educación en la dimensión local no deja de reconocer el municipio como institución con vida propia, articulando mientras, las políticas y acciones educativas a nivel nacional / global, rompiendo con la dicotomía entre el centro y la periferia, local y global, ya que uno está contenido en el otro.

Palabras clave: Historia local. Historia de la educación. Annales. Investigación.

\section{La Novelle Histoire $e^{i}$ e ressurgimento da História Local ${ }^{\mathrm{ii}}$}

Philippe Ariès, um dos nomes notáveis da historiografia francesa, recupera em um de seus escritos, a gênese da História Social francesa quando acontece a renovação da ciência histórica no início do século XX. Era um tempo em que a "história tradicional se interessava quase exclusivamente por indivíduos, por camadas superiores da sociedade, por suas elites (os reis, os homens de Estado, os grandes revolucionários), e pelos acontecimentos (guerras, revoluções), ou pelas instituições (políticas, econômicas, religiosas) dominadas por tais elites" (ARIÈS, 2011, p.273). Nesse cenário, a História Social se apresenta como um contraponto à História Tradicional, tendo o seu campo de investigação voltado para a "massa da sociedade, deixada de lado pelos poderes, por todos aqueles em posição de subjugados” (Op. Cit. p. 273). Tratava-se de romper com a história política de viés positivista, a história historicizante ou événentielle que, por um lado, era o que Le Goff denominou de uma história-narrativa e, por outro, "uma história de acontecimentos, uma história factual, teatro de aparências que mascara o verdadeiro jogo da história, que se desenrola nos bastidores e nas estruturas ocultas (...)" 
(LE GOFF, 1990, p.31). É nessa dinâmica que surge, em 1929, a chamada École des Annales, movimento historiográfico francês agrupado em torno da revista Annales d'Histoire Economique et Sociale, lançada em Estrasburgo no mesmo ano e transferida para Paris, em 1936.

Tendo como fundadores Marc Bloch e Lucien Febvre, a Escola dos Annales se consubstancia como uma corrente inovadora que despreza o acontecimento e insiste na longa duração. Ela se 'evolui' em várias gerações e, após a Segunda Guerra mundial, em 1946, impõe-se com uma nova sigla passando a chamar-se Les Annales. Economies. Societés. Civilizations (BOURDÉ; MARTIN, 1983). Nessa nova versão a sua notoriedade se eleva, sobremodo, com a criação de um instituto de investigação e de ensino, a VI Seção da École Pratique des Hautes Études, em 1947, presidido por Lucien Febvre e, posteriormente, por seu discípulo Fernand Braudel ${ }^{\mathrm{iii}}$.

Ao incorporar pesquisadores de diferentes campos de pesquisa, em uma busca pluridisciplinar, a Escola dos Annales esforça-se por aproximar a História das outras ciências humanas, sobretudo, da Sociologia, da Antropologia e da Geografia. Esta última teve em Braudel o seu mais notável discípulo, a sua obra "O Mediterrâneo e o mundo mediterrânico na época de Filipe II" é a expressão de um historiador impregnado das lições da geografia humana, ou seja, a Escola dos Annales busca na Geografia a construção de uma nova abordagem para a interpretação dos fatos históricos, situando-os não apenas em um tempo histórico, mas, também, em um espaço. Não por acaso, a revista Annales d'histoire économique et sociale, teve como inspiração os Annales de Géographie, de Vidal de La Blache $^{\text {iv }}$ (BURKE, 1991).

Em 1956, Braudel sucede Lucien Febvre no comando dos Annales e conserva as diretivas anteriores, além de se manter fiel às orientações de Bloch": "louva a unidade das ciências humanas, tenta edificar uma 'história total' e mantem a ligação entre o passado e o presente" (BOURDÉ; MARTIN, 1983, p. 131). Depois de 1968, Braudel rodeia-se de um comitê onde figuram Jacques Le Goff, Emmanuel Le Roy Ladurie e Marc Ferro, e é na década de 1970 que a Escola dos Annales alcança a sua terceira geração, sob o comando do medievalista Le Goff em parceria com Georges Duby. Já em 1974, Le Goff, em parceria com Pierre Nora, propõe um novo "Fazer História", título de uma coletânea de artigos que trazem em si a essência dos Annales, posto que os mesmos colocam "novos problemas", esboçam "novas abordagens" e distinguem "novos objetos".

Revista RBBA $\mid$ Revista Binacional Brasil Argentina 
Em 1975, a era Braudel ficou para trás quando a VI Seção da École Pratique des Hautes Études se tornou a École des Hautes Études en Sciences Sociales, presidida por Le Goff, sendo substituído, em 1977, por François Furet (BURKE,1991). Aqui a chamada Nova História emerge como a 'herdeira da Escola dos Annales', conforme apontam Bourdé e Martin e ganha território amplo na pesquisa histórica. Nesse contexto, um novo grupo que se agrega ao antigo: André Burguière, Roger Chartier, Jacques Revel, Jean-Claude Schmidt compõe a "genealogia intelocrática" (BOURDÉ; MARTIN, 1983, p. 140) cuja função, junto ao primeiro grupo, passa a ser a busca legitimadora do espírito dos primeiros Annales.

Não obstante, a Nova História tem “pais”, conforme afirma Le Goff (1990). Para este historiador as "Novas considerações sobre a história", de Voltaire, em 1744, já teciam severas críticas a uma história em que ele "só aprendia acontecimentos", era preciso "saber a história dos homens, em vez de saber-se uma pequena parte da história dos reis e das cortes" (VOLTAIRE, apud LE GOFF, 1990). Também o prefácio dos "Estudos históricos", de Chateaubriand, em 1831, é, para Le Goff, um verdadeiro manifesto da Nova História. Nele o pensador se mostrava insatisfeito com os analistas da antiguidade, posto que esses "não introduziam em suas narrativas o quadro dos diferentes ramos da administração: as ciências, as artes, a educação pública eram rejeitadas do domínio da história” (LE GOFF, 1990, p. 38).

Entretanto, Jules Michelet e Fraçois Simiand são considerados, conforme Le Goff, como os grandes precursores da Nova História. Michelet dirigiu críticas diretas à história como ele a via nos homens eminentes que a representavam. Para ele, a história lhe parecia fraca em seus dois métodos: pouquíssimo material e pouquíssimo espiritual. A sua postura tratava-se da "recusa de uma história essencialmente política e a aspiração a uma história total e profunda" (LE GOFF, 1990, p. 41). Para François Dosse, Michelet foi, de fato, aquele que começou a se interessar pelas bruxas, pelo irracional, pela heresia, pelos excluídos e pela cultura popular (DOSSE, 1992).

Comumente, Simiand em seu memorável artigo "Método histórico e ciência social", tece críticas aos "três ídolos da tribo dos historiadores": "o ídolo político", "o ídolo individual" e "o ídolo cronológico" (LE GOFF, 1990), ou seja, ele denuncia a construção historiográfica em que é dada importância exagerada aos fatos políticos, às guerras, ao estudo de um indivíduo em sua origem particular, ao mesmo tempo em que oculta o fenômeno social, o sujeito comum e as suas relações. 
A Nova História alcança o seu momento de fecunda produção na década de 1970, década em que, conforme Vainfas (1997), a história das mentalidades procurou afirmar-se como campo ou disciplina específica do conhecimento histórico. A história das mentalidades vem responder àqueles que relegam a história à simples descrição dos fenômenos conscientes, com a constituição dessa história "que tem por fundamento o nível inconsciente das práticas sociais, o pensamento coletivo e automático de uma época ou de um grupo social (DOSSE, 1992, p. 173). Essa fase traz consigo uma premissa dos fundadores dos Annales, a de que a prática histórica é inconcebível fora do cotidiano, afinal, o imperativo posto por Bloch e Febvre era o de que longe de encarcerar-se em sua torre de marfim, o historiador deverá abrirse ao mundo exterior, participar ativamente da vida de seu tempo. Essa fase, conforme Burke (1992) não foi apenas a volta aos estudos das mentalidades, mas, principalmente, a tentativa do emprego dos métodos quantitativos na História Cultural, assim como, o retorno da política delineada em uma história de uma nova concepção do fato político, que veio tomar o seu lugar no domínio da Nova História.

Todavia, é incontestável que o movimento dos Annales se prolongou por sucessivas gerações, a ponto de se falar em uma possível quarta geração, que seria a Nova História Cultural, no final dos anos de 1980. Esta fase, liderada pelos historiadores Roger Chartier, Jacques Revel e Lyn Hunt, além do italiano Carlo Ginzburg que se soma ao grupo, busca a investigação das "práticas culturais", indo além das "mentalidades". Nesse horizonte, Jim Sharpe aponta a "história vista de baixo" como mais um projeto nascido da influência dos Annales e que se comprovou extraordinariamente frutífero, na medida em que "abre a possibilidade de uma síntese mais rica da compreensão histórica, de uma fusão da história da experiência do cotidiano das pessoas com a temática dos tipos mais tradicionais de história" (SHARPE, 1992, p. 54). Para esse autor um dos propósitos da história é prover aqueles que a escrevem ou que a leem um sentido de identidade, de sua origem e a "história vista de baixo" pode desempenhar um papel importante nesse processo "recordando-nos que nossa identidade não foi estruturada apenas por monarcas, primeiros-ministros ou generais" (SHARPE, 1992, p. 60).

É nesse movimento de intermitentes gerações que a Escola dos Annales abre espaço para o estudo do local. Delimitar, explicar as lacunas, os silêncios da história, e assentá-la tanto sobre os vazios, quanto sobre os cheios que sobreviveram (LE GOFF, 1990) constitui uma das tarefas nobres da Nova História. Nessa perspectiva, Febvre toma para si a lição de 
Vidal de La Blache e procura lançar uma ponte entre a História e a Geografia. Vem de Febvre a sugestão de "separar, por comparação ou abstracção, o papel nas histórias humanas de um certo número de factores qualificados, especialmente de geográficos: a distância, o espaço, a posição" (BOURDÉ; MARTIN, 1983, p. 120). Tratava-se de uma via aberta à geo-história que, por sua vez, atingira a produção braudeliana, posto que a Geografia lhe permitiu valorizar a longa duração. Em sua obra ela amenizou o peso do homem como ator da história ao substitui-lo por um sujeito espacial, no caso, o Mediterrâneo, transformado ele próprio em sujeito da história. Entretanto, o meio geográfico tem por função manter juntos, agrupar os elementos esparsos do organismo geral, ele produz e determina uma vida comum, assim sendo o meio e o espaço da geografia de Vidal de La Blache, tomada de empréstimo por Febvre e Braudel, legou um campo fértil para o estudo regional e local. Essa nova tendência que abordaria o 'pequeno espaço' se fortalece nos anos de 1950 e ficou conhecida na França como 'História Local' (BARROS, 2006).

É nessa esteira que, também, seguem as produções historiográficas no campo da demografia. A Escola dos Annales descobre o domínio da história demográfica, que assenta em séries de nascimentos, de casamentos e de falecimentos, logo depois da Segunda Guerra, e encontra-se em várias teses, conforme asseveram Bourdé e Martin (1983). É o que faz Pierre Gourbet em uma de suas mais notáveis produções: Beauvais e o Beauvaisis nos séculos XVI ao XVIII, cuja contribuição para os estudos historiográficos locais é incontestável.

\section{A História Local e história da educação}

Ao longo do século XX, muitas ciências se modernizaram em um setor particular de seu domínio, sem que por isso todo o seu campo fosse modificado. A ciência histórica, em particular, rompeu barreiras, avançou fronteiras, alcançando os mais longínquos rincões das ciências humanas e sociais. Nesse horizonte, um trabalho demasiado rico é o do historiador Pierre Goubert, já mencionado.

A tese de Goubert Beauvais e o Beauvaisis de 1600 a 1730 (1960) põe em evidência uma façanha da demografia histórica: a de que ela foi capaz de inventar os seus próprios métodos. É nesse trabalho que ele marca uma viragem historiográfica e, ademais, oferece um modelo para avaliar o movimento de populações em um tempo em que não se pensava na precisão das estatísticas. Barros (2004) considera que Goubert foi pioneiro em entrelaçar a

\begin{tabular}{l|l} 
Revista RBBA & Revista Binacional Brasil Argentina
\end{tabular} 
História Demográfica e a História Regional, na medida em que a sua obra focaliza uma região francesa o século XVII. Segundo ele, trata-se de uma História Regional cuidadosamente articulada com uma Demografia Histórica que se desdobra em uma verdadeira análise social, atentando aos aspectos econômicos (BARROS, 2004). Para Bourdé e Martin (1983), Goubert não renunciou à procura do global, mas quis atingi-lo numa base espacial mais restrita, no âmbito de estudos regionais. Essa premissa se confirma no fato de que em sua obra, o todo de uma sociedade é estudado e apresentado com notável rigor científico e pormenores.

Goubert foi um dos discípulos de Bloch que adotou "o espírito dos Annales" e, embora tenha se especializado na história do século XVII, ao estudar com Bloch permaneceu fiel ao estilo da história rural de seu mestre ${ }^{\mathrm{vi}}$. Todavia, é em seu eminente artigo publicado originalmente na obra Historical Studies Today vii (1972), intitulado “A História Local”, que Pierre Goubert problematiza a pesquisa histórica elegendo como foco de discussão a história local. Nesse artigo, o historiador francês denomina a história local como

aquela que diga respeito a uma ou poucas aldeias, a uma cidade pequena ou média (um grande porto ou uma capital estão além do âmbito local), ou a uma área geográfica que não seja maior do que a unidade provincial comum (como um county inglês, um contado italiano, uma Land alemã, uma bailiwick ou pays francês) (GOUBERT, 1992, p.01).

Segundo ele, a História Local teve os seus tempos áureos na França. Praticada com cuidado, zelo, e até orgulho, ela foi mais tarde desprezada, principalmente nos séculos XIX e primeira metade do XX, pelos partidários da história geral, cujos métodos históricos usuais se ocupavam dos problemas das classes mais altas, ou seja, de uma história "interessada nos que fizeram as leis (...), naqueles que governavam e não nos governados, no clero e não nos fiéis, nas histórias de homens de letras descrevendo suas regiões e não na própria realidade da região" (GOURBET, 1992, p.48). Não obstante, respaldada pelo novo olhar da Nova História que elege "novos problemas" e "novos objetos" para a pesquisa, a história local ganha território amplo nas pesquisas históricas. Essa nova postura diante do "fazer histórico", possibilitou a abertura de novas fronteiras interpretativas, alargando o conceito de fontes, assim como, possibilitando ao pesquisador fazer do vivido cotidiano da história um objeto científico, sem perder de vista, a amplitude da sociedade. Nessa perspectiva, a História Local enquanto possibilidade teórico-metodológica lançada pela Nova História, vem se contrapor a uma história que "foi escrita a partir do centro" (CERTEAU, apud SCHMITT, 1990, p. 395) e 
busca trazer para a cena histórica o sujeito da "história vista de baixo". Assim, a História Local retorna à cena a partir de um novo interesse da História Social, qual seja, "a História de toda uma sociedade, não apenas dos privilegiados que a governaram, julgaram, oprimiram, ensinaram" (GOURBET, 1992, p.48). Em síntese, do macro-espaço que abriga civilizações, a historiografia moderna traz para a pesquisa a possibilidade de examinar os micro-espaços que abrigavam populações localizadas, fragmentos de uma comunidade nacional mais ampla. Assim sendo, veio com esse "novo fazer histórico" a possibilidade de ampliar a discussão e, até, corrigir as grandes formulações já propostas na produção historiográfica em nível nacional. Por conseguinte, a História Local não se opõe à história global ou a "macro história”, o seu recorte apenas designa uma delimitação temática marcada por particularidades históricas, culturais, políticas, etc., quase sempre, ocultadas por generalizações maiores. A grande valia da história local está, sobretudo, em seu diálogo fecundo com a história global, posto que

não existe (...) hiato, menos ainda oposição, entre história local e história global. O que a experiência de um indivíduo, de um grupo, de um espaço permite perceber é uma modulação particular da história global. (...) o que o ponto de vista microhistórico oferece à observação não é uma versão atenuada, ou parcial, ou mutilada, de realidades macrossociais: é uma versão diferente. (REVEL, 1998, p. 16).

Comumente, a história em sua abordagem local abriga também o aspecto regional. Aqui também a contribuição da Geografia derivada de Vidal de La Blache destaca-se com particular nitidez, ajudando a definir um conceito de Região, posteriormente, apropriado pelos historiadores para o estudo de micro-espaços, em muitos sentidos, "dotados de uma homogeneidade bem maior do que os macro-espaços que haviam sido examinados por Braudel" (BARROS, 2006, p. 11).

Conforme Janaína Amado, região aqui é entendida como "a categoria espacial que expressa uma especificidade, uma singularidade, dentro de uma totalidade: assim, a região configura um espaço particular dentro de uma determinada organização social mais ampla, com a qual se articula" (AMADO, 1990, p. 13). Outrossim, Pesavento (1990), amparada nos pressupostos do materialismo dialético, afirma ser a história regional a síntese das múltiplas determinações, ou seja, existe uma especificidade localizada que é econômico-social, como espaço de exercício do poder e de construção da autoimagem de um grupo. Sendo assim, o 
estudo histórico de uma região implica a análise de uma singularidade na totalidade (PESAVENTO, 1990).

Não obstante, em busca de seu reconhecimento enquanto gênero historiográfico, a História Local (e regional) se viu sob olhar exigente de diferentes críticos, como aborda Barros (2005). Segundo este historiador, com o progressivo surgimento dos novos problemas e objetos oferecidos pela expansão dos domínios historiográficos no decurso do século XX, o modelo de região derivado da escola geográfica de La Blache começou a ser questionado, visto que deixava encoberta a questão essencial de que qualquer delimitação espacial é sempre uma delimitação arbitrária, e também de que as relações entre o homem e o espaço modificam-se com o tempo, tornando 'não-operacionais' delimitações regionais que poderiam funcionar para um período, mas não para outro, implicando em deixar escapar uma série de objetos historiográficos que não se ajustam a estes limites (BARROS, 2005). Também Neves (2008) denuncia que até recentemente, os historiadores em geral, e os da Península Ibérica e da América Latina, em particular, "reportavam-se à história regional e local como um recurso desprezível da pesquisa histórica, uma solução para registros de memórias e crônicas (...)" (NEVES, 2008, p. 29), de modo que os historiadores profissionais negavam quaisquer méritos ao objeto local como artifício da investigação histórica (MARTÍN GELABERT, 2001, apud NEVES, 2008). Nessa perspectiva, vale salientar que a história local e regional, em sua formulação contemporânea, embora tenha o seu remoto antecedente nas anotações sobre histoire rurale régionale et histoire locale, de Marc Bloch (1961, p. XXX-XXXIII), e tenha se desenvolvido, posteriormente, com as monografias dos já citados Le Roy Ladurie e Pierre Goubert, elaboradas como paradigmas de uma história regional geral, cuja sustentação estava na perspectiva da longa duração braudeliana, essa abordagem não apresenta a dimensão geográfica como foco, ou lhe atribui o papel de condutora da ideia, como fizera Braudel. $\mathrm{O}$ objeto de estudo da História Local e Regional volta-se para o homem no seu cotidiano historicamente construído, e não o espaço, como propunha estudar o paradigma inicial (HUNT, 1992), para situar-se nas ações humanas tecidas no espaço de uma região ou localidade.

É bem verdade que, ao recorrermos ao célebre artigo de Goubert (1992), vemos que o mesmo aponta para o fato de que a emergência da História Local dos anos 1950 havia sido motivada precisamente por uma combinação entre o interesse em estudar uma dimensão social mais ampla e alguns métodos que permitissem este estudo para regiões mais Revista RBBA $\mid$ Revista Binacional Brasil Argentina 
localizadas. Ao trabalhar em suas pequenas localidades, os historiadores poderiam desta maneira fixar sua atenção "em uma região geográfica particular, cujos registros estivessem bem reunidos e pudessem ser analisados por um homem sozinho" (GOUBERT, 1992, p.49). Não obstante, a coincidência entre a região examinada e uma unidade administrativa tradicional como um pequeno município, permite por vezes que o historiador resolva as suas carências de fontes em um único espaço, ali mesmo se apropriando de informações concernentes às relações que plasmaram os grupos sociais investigados, sem, contudo, 'mirarse na árvore e, ao mesmo tempo, ocultar a floresta'.

No horizonte da pesquisa em História da Educação, a História Local traz contribuições relevantes, a despeito de, ainda, haver resistência por parte de alguns estudiosos da História, de não reconhecerem a educação como um domínio da investigação histórica (CORSETTI, 2006; SAVIANI, 1998). Não obstante, ao pensarmos o local como um espaço de abrangência geográfica restrita, cujos sujeitos e práticas sociais expressam hábitos, costumes, tradições que lhes conferem uma identidade, a educação emerge como uma amálgama social importante, cuja função, em especial na dimensão municipal, está voltada tanto para o desenvolvimento social e econômico, quanto para a legitimação do poder local. Nessa perspectiva, ao definirmos o local como o lugar, o contexto, a agência, os sujeitos/beneficiários, o projeto/investimento (CARVALHO; CARVALHO, 2012), vemos que a pesquisa histórica, na área de História da Educação em uma dimensão micro, focaliza o município como uma instância do planejamento e consolidação de projetos educativos, escolares, político-pedagógicos com características próprias, além de trazer para a cena histórica os sujeitos que idealizam, planejam, realizam e disputam espaços de poder, por fim, nos remete ao significado da ação histórica protagonizada por esses agentes. Com o foco nas ações locais, do ponto de vista educacional, como as nomeações de professores, a construção de escolas em lugares específicos, a influência de chefes de famílias tradicionais locais nas políticas educacionais, o apadrinhamento na contratação dos profissionais da educação, as parcerias público-privado, etc., a escrita da história da educação na dimensão local não deixa de reconhecer o município como instituição com vida própria, entretanto articulado com as ações políticas e educacionais em nível nacional/global, rompendo com a dicotomia entre o centro e a periferia, o local e o global, posto que um está contido no outro. Ademais, a pesquisa com História Local ao eleger a História da Educação como objeto propõe um outro ângulo de análise desse fenômeno nos limites da municipalidade, servindo para "alterar \begin{tabular}{l|l} 
Revista RBBA & Revista Binacional Brasil Argentina
\end{tabular} 
nossas percepções sobre o passado" (GOUBERT, 1992, p. 50) e trazendo à tona o que o pesquisador português Justino Magalhães denominou de "município-pedagógico"viii (NETO; CARVALHO, 2015, p.45), com todas as nuances do seu campo semântico.

A História Local e Regional evoluiu, portanto, de uma situação de desprezo para outra de relativo sucesso acadêmico, com crescimento substancial da investigação histórica pela academia, em fecundo diálogo com outros campos epistemológicas. A História Local e Regional alcança, assim, o seu lugar na pesquisa em História da Educação, comumente protagonizada por sujeitos que representam a "história vista de baixo". Ela constitui-se, numa

\footnotetext{
proposta de investigação das atividades cotidianas de comunidades conectadas historicamente num território, conscientes do pertencimento a ele, (...) como meio de se alcançar o conhecimento de viveres e saberes em dimensões inatingíveis por outras abordagens sistêmicas ou de abrangências espaciais mais amplas (NEVES, 2002, p. $45)$.
}

Em suma, a realidade histórica, em qualquer época, é indubitavelmente complexa. Outrossim, essa complexidade não pode ser integralmente captada por nenhuma das ciências humanas, por mais que estas desenvolvam novos métodos para tentar apreender a realidade a partir de perspectivas cada vez mais enriquecidas. Assim sendo, essa dimensão da pesquisa histórica, ora discutida, contribui para a desmitificação de determinadas "certezas", ao negar alguns postulados generalizadores, ao mesmo tempo em que nega ser autossuficiente, e, embora não se possa sustentar que a História geral ou estadual sejam somas das histórias locais, é certo que as generalizações nunca serão seguras se não se levar em conta os desenvolvimentos locais.

\section{Referências}

AMADO, Janaína. História e região: reconhecendo e construindo espaços. In: SILVA, Marcos A. da. República em migalhas: história regional e local. São Paulo: ANPUH; Marco Zero; Brasília: CNPq, 1990.

ARIÈS, Philippe. A História das mentalidades. In: NOVAIS, Fernando A.; SILVA, Rogério F. da. (Org.) Nova História em perspectiva. São Paulo: Casac \& Naify, 2011.

BARROS, José d'Assunção. O campo da história: especialidades e abordagens. Petrópolis: Vozes, 2004. 
História, Região e Espacialidade. In: Revista Brasileira de História Regional. Ponta Grossa: UEPG, 2005. vol.10, n 1, p.95-129.

BOURDÉ, Guy; MARTIN, Hervé. As escolas históricas. Portugal: Fórum da História, 1983. BURKE, Peter (org.). A Escrita da História, novas perspectivas. São Paulo: UNESP, 1992. CARDOSO, Ciro Flamarion; VAINFAS, Ronaldo (Orgs.). Domínios da história: ensaios de teoria e metodologia. Rio de Janeiro: Campus, 1997.

CARVALHO, Carlos Henrique de; CARVALHO, Luciana Beatriz de Oliveira Bar de. O município e a educação no Brasil, as ações da Câmara Municipal de Uberabinha-Minas gerais (1890-1920). In: NETO, Wenceslau Gonçalves; CARVALHO, Carlo Henrique de (Orgs.). O município e a educação no Brasil, Minas gerais na Primeira República. Campinas, SP: Alínea, 2012.

CORSETTI, Berenice. A análise documental no contexto da metodologia qualitativa: uma abordagem a partir da experiência de pesquisa do Programa de Pós-Graduação em Educação da Unisinos. UNIrevista, São Leopoldo, v. 1. n. 1, p. 32-46, jan. 2006.

DONNER, Sandra Cristina. História LocaL: discutindo conceitos e pensando na prática. O Histórico das produções no Brasil. In: XI Encontro Estadual de História, História, memória e Patrimînio, Anpuh. UFRGS. Porto Alegre: 2012.

DOSSE, François. A História em Migalhas, São Paulo: Editora Ensaio, 1994.

GOUBERT, Pierre. História local. História \& Perspectivas, Uberlândia, n.6, p.51-52, jan/jun., 1992.

HUNT, Lynn. Apresentação: história, cultura e texto. In: A Nova História Cultural. 2 ed. São Paulo: Martins Fontes, 1992.

LE GOFF, Jacques. A História Nova. São Paulo: Martins Fontes, 1990.

NETO, Wenceslau Gonçalves; CARVALHO, Carlos Henrique de. (Orgs.) Ação municipal e educação na Primeira República no Brasil. Belo Horizonte: Mazza, 2015.

NEVES, Erivaldo Fagundes. História regional e local: fragmentação e recomposição da História na crise da modernidade. Feira de Santana: UEFS; Salvador: Arcádia, 2002.

PESAVENTO, Sandra Jatahy. História regional e transformação social. In: SILVA, Marcos A. da. República em migalhas: história regional e local. São Paulo: ANPUH; Marco Zero; Brasília: CNPq, 1990. p. 67-79.

REVEL, Jacques. Jogos de escolas: a experiência da microanálise. Rio de Janeiro: FGV, 1998. 
SAVIANI, Dermeval. História das idéias pedagógicas no Brasil. 2. ed. Campinas, SP: Autores Associados, 2008.

SCHMITT, Jean-Claude. A história dos marginais. In: LE GOFF, Jacques. A História Nova. São Paulo: Martins Fontes, 1990. p.261-290.

SILVA, Marcos A. da. República em migalhas: história regional e local. São Paulo: ANPUH; Marco Zero; Brasília: CNPq, 1990.

SHARPE, Jim. A História vista de baixo. In: BURKE, Peter. A escrita da História. Novas perspectivas, São Paulo: Unesp, 1992.

\section{Notas}

\footnotetext{
i A expressão "Nova história" é mais bem conhecida na França. La Nouvelle Histoire é o título de uma coleção de ensaios editada, em 1978, pelo renomado medievalista francês Jacques Le Goff. (BURKE, 1992). Na tradução em português a expressão foi invertida no título.

ii $\mathrm{O}$ termo História Local utilizado aqui, refere-se a um gênero historiográfico, com temática, público alvo e "regras" próprias, já o termo 'história local' trata-se da produção historiográfica com recorte local (DONNER, 2012).

iii Fernand Braudel, considerado um dos maiores historiadores do século XX e um dos nomes notáveis da chamada Escola dos Annales, nasceu em uma pequena aldeia no leste da França, Luméville-em-Ornois, em 1902, e faleceu em 1985, em Cluses. Em decorrência da $2^{\text {a }}$ Guerra Mundial, Braudel foi preso, em 1940, e enviado à Alemanha. Enquanto prisioneiro de guerra em um campo perto de Lübeck, Braudel dedicou cinco anos para escrever a sua obra de maior destaque: La Méditerranée et le monde méditerranéen à l'époque de Philippe II (O Mediterrâneo e o Mundo Mediterrânico à época de Filipe II), defendida em 1947 como tese de doutorado. Braudel atuou como professor na recém-criada USP, de 1935 a 1937. (Cf. Marcos Antônio Lopes (Org). Fernand Braudel, tempo e história. Rio de Janeiro: FGV, 2003).

iv Paul Vidal de La Blache foi um influente geógrafo francês, que viveu entre 1845 e 1918. É considerado o fundador da geografia francesa moderna e da corrente francesa de geografia humana. Os seus estudos influenciaram gerações de historiadores, em especial os da Escola dos Annales, sobretudo no período pósSegunda Guerra, surgindo daí o paradigma denominado "geo-história" (Cf. François Dosse. A História em migalhas. São Paulo: Ensaio; Campinas, SP: Ed. UNICAMP, 1992).

${ }^{\vee}$ Durante a Segunda Guerra Mundial, Bloch, embora já tivesse 53 anos, alistou-se no exército. Após a derrota francesa retornou, por pouco tempo, à vida acadêmica, acabando por engajar-se na Resistência, na qual desempenhou um papel ativo até a sua captura pelos alemães. Foi fuzilado em 1944. (BURKE, 1991).

${ }^{v i}$ BLOCH, Marc. Les caractères originaux de l'histoire rurale français. 3. tirage. Paris: Librarie Armand Colin, 1960, t. I, p. XI - XIII, 1. ed. Oslo, 1931.

vii GILBERT, Felix; GRAUBARD, Stephen Richards. Historical Studies Today. New York/London, W.W. Norton \& Company, 1972, pp. 300-313.

viii Conforme o autor, o termo Município-pedagógico implica em um município administrativo e um município social a partir do que as "autarquias projectaram, idealizaram e puseram em marcha programas de educação e instrução, num quadro de complemento da acção estatal, mas frequentemente também levando a sua autonomia até a criação de uma oferta educativa própria que incluía a rede escolar, os professores, os cursos profíssionais" (p. 45). MAGALHÃES, Justino. O município liberal e a decisão política. In: NETO, Wenceslau Gonçalves; CARVALHO, Carlos Henrique de. (Org.). Ação municipal e educação na Primeira República no Brasil. Belo Horizonte: Mazza Edições, 2015.p. 37-46.
} 


\section{Sobre a autora}

Mestre em Educação pela Pontifícia Universidade Católica de Minas Gerais, PUC/Minas, doutoranda em Educação na mesma universidade; Professora Assistente da Universidade Estadual do Sudoeste da Bahia - UESB; membro do Grupo de Estudos e Pesquisa sobre Profissão Docente - GEPPDOC - PUC/Minas; e Coordenadora do Grupo de Estudos em História da Educação Brasileira GESTHEB/UESB. 